\title{
La norma rectora o constitución como instrumento del derecho planetario
}

\section{The guiding rule or constitution as instrument of planetary law}

AUTOR: José de Jesús Covarrubias Dueñas

SUMARIO: I. Conceptos básicos y problemática. II. Marco constitucional actual en México. III. Conclusiones. IV. Propuestas. V. Bibliografía.

Resumen: La Constitución, bajo el paradigma de la Revolución francesa, es el acta de nacimiento del Estado de Derecho y es el documento por el que nace el Estado, sujeto del Derecho Internacional, Supranacional y Planetario. Los contenidos de la primera Constitución o Norma Rectora del Planeta, la de los EUA, se interrelacionan con dichas normas interna y externas, con interrelaciones ad intra et ad extra. Ahora, con la influencia de hegemonías y entes internacionales, supranacionales y de otros tipos, los países tienen que armonizar sus normas internas a las del exterior, pero los pueblos no manifiestan su soberanía, aprobación y por tanto, tienen que acatar normas del extranjero violentando su libertad política, elemento básico de la República democrática y representativa.

Palabras clave: Constitución, Estado, Estado de Derecho, planeta.

Abstract: The Constitution, under the French Revolution paradigm, is the birth certificate of the Rule of Law and it is the document that gives life to the
State as a subject of International, Supranational and Planetary law. The contents of the first constitution, The US Constitution, internal and external laws interrelate, ad intra et ad extra interrelation, Now, due to the influence of Supremacies, international, and supranational entities, countries have to match their laws to international laws, without the consent of the people and they have to comply, and that violated their political liberties, which are a basic element of a democratic and representative Republic.

Key words: Constitution, State, Rule of Law, Planet.

\section{Conceptos Básicos y Proble- mática:}

1.1. ¿Qué es la Norma Rectora? La palabra norma entraña la protección de valores, principios, intereses y lo que una comunidad o agrupación humana en un tiempo y espacio determinados, trata de preservar y proyectar hacia las nuevas generaciones porque consideran que dichas creaciones culturales son necesarias para resolver los problemas que puedan ser planteados por las nuevas generaciones, así, también las normas encierran experiencia, principios, historia, medios, memoria colecti- 
va, objetos, fines o teleología y valores a proteger de dicha agrupación humana. Por ello, las normas dentro de dicho contexto comunitario, social o entre personas, son de diversa índole y son la resultante de procesos dialécticos interminables en donde se yuxtaponen normas políticas, religiosas, económicas, jurídicas y sociales.

Así, las Normas Rectoras son las que han existido en toda agrupación humana, desde los pactos, contratos o convenios sociales, las psefismata, Los Vedas, Sudras, El Código de Hammurabi, El Código de Manú, mandamientos, Códices Mesoaméricanos o Costumbres de los pueblos originarios de los diversos territorios planetarios, El Taoísmo y Confucionismo, Pactos de la Santa Alianza, El Corán, Digesto o Pandectas, Corpus luris Civilis, Corpus luris Canonici, Magnas Cartas, Fueros, Leyes de Indias y demás normas que han regido a diversos pueblos, comunidades, sociedades y agrupaciones humanas en todo el planeta, que hoy se denominan Constituciones.

1.2. ¿Qué es una Constitución? Conforme a la Déclaration des Droits de I'Homme et du Citoyen, 26 août 1789, a la Declaración de los Derechos del Hombre y del Ciudadano, del 26 de agosto de 1789, en su artículo 16, se estableció que: Toute société dans laquelle la garantie des droits n'est pas assurée, ni la séparation des pouvoirs déterminée, ná point de Constitution = Toda sociedad en la que la garantía de los derechos no está asegurada, ni la separación de los poderes determinada, no tiene Constitución. Así, conforme a dicho paradigma, la Constitución es el acta de nacimiento del Estado.

De lo anterior, se establece el Estado de Derecho, de acuerdo, mediante pacto o contrato social soberano, en virtud a que la soberanía nacional reside esencial y de manera original en el pueblo, todo poder público fluye del pueblo y es para resolver las necesidades y problemática de su gente, de los que con sus impuestos mantienen a las instituciones; por ello, las personas tienen, en todo momento el sagrado, inalienable, imprescriptible e indivisible derecho de establecer, cambiar o determinar, en el momento que juzgue pertinente a su gobierno, a la forma de gobierno y a su Norma Rectora.

En este sentido, la soberanía o el poder del pueblo, se manifiesta ad intra et ad extra = en lo interno y en lo externo, en cuanto a las decisiones del Constituyente Originario y el Extraordinario, de las formas de gobierno, de los poderes y sus atribuciones, los niveles de gobierno y competencias y toda la estructura del Estado de Derecho que se 
instituye para la protección de los derechos de las personas y de los ciudadanos, fin primordial de todo ente jurídico, ya que los derechos del hombre son la base y el objeto de las instituciones.

Así, una Constitución o Norma Rectora, es un pacto o compromiso político celebrado o acordado por un pueblo en un contexto histórico determinado para proteger los valores, principios e intereses más trascendentes, que son los sagrados, inalienables, imprescriptibles e indivisibles derechos de las personas; para lo cual se instituyen poderes formales y niveles de gobierno, que de manera lamentable, han sucumbido ante los poderes económicos, con lo que el proceso de deshumanización y de depredación del planeta se encuentra en marcha y que por tanto, debemos seguir evitando más daños irreparables al planeta, a la especia humana y demás seres vivos inter y extra planetarios con los que nos encontramos en interrelaciones interdependencia.

Respecto a las manifestaciones del Estado de Derecho $=R e-$ chtsstaat, ad extra o hacia el exterior, se considera a la soberanía (supra, super = sobre, encima y omnis = todo, todos), como una manifestación de la libertad política del Estado de Derecho, de autodeterminación, de independencia o de que su pueblo, mediante la expresión de sus poderes formales y del voto de la gente manifestado en plebiscito o refrendo, toman acuerdos, pactos, contratos, tratados, convenios o compromisos internacionales o supranacionales, que implican derechos y obligaciones de los Estados, entendidos como personas jurídicas en diversos ámbitos como pudiesen ser, el ámbito internacional, supranacional o planetario.

1.3. ¿Qué es el Derecho Planetario? Al hilo de lo anterior, tenemos que un Estado de Derecho $=$ Rechtsstaat, es en sujeto de Derecho Internacional, Supranacional o Planetario, dado que al nacer los Estados estamos ante el nacimiento de las personas o sujetos jurídicos a través de los cuales se crea, realiza, nace, formula, convenia, pacta, contrata o realiza los Tratados o instrumentos que originan las normas supraestatales y como ya lo hemos patentado: La Norma Rectora o Constitución, es el acta de nacimiento del Estado de Derecho.

Además, cada Norma Rectora o Constitución, desde la primera y paradigmática The Constitution of the United States of America $=\mathrm{La}$ Constitución de los Estados Unidos de América, del 17 de septiembre de 1787, se instituyó, de manera clara, como un documento interno y externo, tal como lo expresan contenidos como el del artículo sexto, 
segundo párrafo, que desde entonces, señala: This Constitution, and the laws of the United States which shall be made in pursuance thereof; and all treaties made, or which shall be made, under the authority of the United States, shall be the supreme law of the land; and the judges in every state shall be bound thereby, anything in the Constitution or laws of any State to the contrary notwithstanding = Esta Constitución, $y$ las leyes de los Estados Unidos que se realicen conforme a ella; $y$ los tratados realizados o que puedan ser realizados, bajo la autoridad de los Estados Unidos, podrán ser la ley suprema de la tierra; y los jueces en cada Estado podrán aplicarlos en forma inmediata, si cualquier Constitución o ley de cada Estado es contraria a lo establecido.

Por lo anterior, está clarísimo, desde entonces, la supremacía constitucional y el control difuso que en nuestro país, parece que, por no saber leer y entender, todavía debatimos absurdos y no se ha captado que dicha pirámide de jerarquía constitucional o de la Norma Rectora, ya estaba implícita y expresa en dicho precepto de la Constitución de los EUA.

Es por ello, que si interrelacionamos los siete artículos de la primera Norma Rectora o Constitución en el planeta bajo el actual paradigma, que es internacional, entonces, queda claro que existe un poder formal que representa al Estado, existe un Jefe de Estado, de igual forma, se crea un órgano legislativo orientado a coadyuvar con el Ejecutivo a las cuestiones internacionales, todo el legislativo, deberá velar por los compromisos internacionales, en especial los económicos y los guerra y el Poder Judicial, deberá hacer la defensa jurídica internacional del Estado; entonces, queda muy claro que la Norma Rectora o Constitución y sus poderes formales establecidos, tienen connotaciones muy claras de órganos difusos del orden internacional, hoy supranacional y planetario.

Lo anterior, ha sido adoptado, aceptado, recibido, aplicado, observado y ejecutado por casi doscientas Normas Rectoras o Constituciones que existen en el planeta; por lo que podemos afirmar de aceptación soberana, interna y externa de dichos paradigmas y por tanto, las Normas Rectoras o Constituciones de cada país, son instrumentos jurídicos internacional y forman parte de la complejidad del Derecho Planetario, que existe, es real, está vivo y se encuentra dentro de un procedimiento dialéctico interminable, imparable y que no sabemos a dónde arribará, pero debemos estudiarlo de manera científica y establecer las bases, los valores, principios e intereses del derecho planetario, del orden común planetario, del bienestar del planeta, del interés planetario. 
Entonces, el derecho planetario, son las normas que han sido creadas los por Estados de Derecho, con el poder soberano de cada pueblo y que han aceptado proteger, salvaguardar, respetar y hacer efectivos los sagrados, inalienables, imprescriptibles e indivisibles derechos de las personas; tal como se desprende del análisis de 196 Normas Rectoras o Constituciones.

De igual forma, nos hemos comprometido a proteger las especies vivas y debemos avanzar en la protección del planeta, nuestra nave espacial, que no tiene dueño, no es de ningún país, persona, trasnacional o poder humano, de manera afortunada; pero lo cierto es que el narcicismo y egocentrismo humano, se ha limitado a crear normas androcéntricas, en la homomensura, de lo cual debemos crear un derecho y normas integrales, dentro de las cuales, un valor, principio e interés, somos los seres humanos, pero existen más seres vivos, como lo es el planeta, nuestro hogar común que está desprotegido y que debemos iniciar un proceso de cuidarlo, protegerlo, respetarlo y amar al ente que todo nos da y le regresamos lo peor de nosotros, debemos cambiar nuestra actitud ante el gran ser que es nuestro planeta y su entorno, del cual ignoramos bastante, además de que todavía no lo conocemos.

1.4. Problemática. De lo anterior, se desprenden algunas contradicciones en el sentido de que la soberanía es del pueblo y que entonces, son las personas dentro de un espacio y tiempo determinados los que determinan sus normas y forma de gobierno; sin embargo, dadas las hegemonías actuales, como el FMI, el BID y otros organismos internacionales, intervienen, de manera directa en decisiones que afectarán de manera directa o indirecta a la población no sólo del país en cuestión, sino a cualquier agrupación humana, país, Estado o Nación, incluso a estructuras supranacionales, lo cual es muy grave y existe una notable tensión entre si deben ser los ciudadanos quienes tomen las decisiones, los poderes de hecho o quienes detenten el mando de estructuras internacionales o supranacionales.

En el mismo sentido, se podrían construir formas mixtas de la toma de decisiones o de cesiones de soberanía, lo más grave, en el caso de nuestro país es que las decisiones respecto de los Tratados Internacionales se encuentran en manos del Senado de la República, del Ejecutivo Federal y de la Suprema Corte de Justicia de la Nación, lo cual es muy delicado y no se toma en cuenta la soberanía nacional en cuanto a consulta al pueblo, plebiscito o refrendo o cualquier otra 
forma en que el pueblo de México pudiese externar su opinión.

\section{Marco Constitucional actual en México:}

Como es sabido México, se ha adherido a la Organización de Estados Americanos (OEA), desde sus antecedentes en el Siglo XIX; a la Organización de las Naciones Unidas (ONU, 1945); al Pacto Internacional de Derechos Civiles y Políticos (PIDCP, 1966) y a la Convención Americana de Derechos Humanos (CIDH, 1969), entre otros compromisos internacionales, por lo que nuestra Norma Rectora se ha venido armonizando a dicho espectro internacional, supranacional y planetario. A continuación, se expresan los artículos de la Norma Rectora o Constitución interrelacionados a los Tratados Internacionales:

2.1 Artículo primero: En dos ocasiones:

- Párrafo primero: Se establece en nuestra Norma Rectora que todas las personas gozarán de los derechos de los humanos que reconoce la Ley Fundamental y los Tratados Internacionales signados por la República; de igual forma, se reconocen las garantías mediante las cuales deben ser protegidos y respetados dichos derechos, salvo los casos de excepción previstos en el artículo 29 de la propia Norma Rectora del país. Lo anterior nos deja muy en claro que nuestra Carta Magna, se encuentra dentro de un proceso de armonización a las normas, acuerdos, tratados y compromisos que ha venido adquiriendo con entes del exterior, acuerdos en los cuales no ha participado el pueblo de México mediante figuras como el plebiscito o el refrendo.

- Párrafo segundo: Se regula que la interpretación de la Norma Rectora y los Tratados Internacionales cuando se analicen los derechos de las personas o de los humanos, será armónica a la Constitución y bajo los principios de pro persona, pro homine y pro femmine, en todo caso, conforme al mayor beneficio que le proporcione la norma aplicable al caso concreto. Lo anterior deviene de la jurisprudencia pronunciada por el Bundesverfassungerichte = Tribunal Constitucional Federal, o Tribunal Constitucional Alemán, quienes hay acuñado la interpretación conforme o Verfassunkonform, que significa el estudio, análisis o dictado de una sentencia o resolución de manera armónica a la Norma Rectora, lo cual implica un estudio profundo del Volksgeist y de elementos nomológicos, históricos, 
sociológicos, hermenéuticos y demás instrumentos para interpretar e manera adecuada, en un tiempo y espacio, una determinada norma.

2.2 Artículo quince. Se prohíbe la celebración de Tratados Internacionales por nuestro país en los cuales se violenten los derechos de los humanos o que se alteren los valores, principios, intereses o disposiciones que establece nuestra Norma Rectora. Lo anterior es armónico a que México no deberá celebrar Tratados Internacionales con países esclavistas o la extradición de reos políticos, como ya es su tradición jurídica, cuando se dio asilo a españoles en la década de 1930 y a chilenos en la década de 1970, entre otros casos históricos, política que sigue vigente en nuestro país que es pacifista.

2.3 Artículo dieciocho. Dispone que podrán trasladarse reos entre México y otros países conforme a los Tratados Internacionales celebrados y siempre y cuando exista el consentimiento expreso del recluso; en el caso de que inmigre un reo mexicano del extranjero, deberá cumplir su condena con base a los sistemas de reinserción social establecidos. Nuestro sistema penitenciario debe ser perfeccionado y antes de reinsertar, deberíamos adaptar o "insertar", lo cual no hemos logrado desde la nula atención a niños, adolescentes y jóvenes.

\subsection{Artículo setenta y seis:}

- Fracción primera: Se señala como facultad exclusiva del Senado de la República, la aprobación de los Tratados Internacionales y las convenciones diplomáticas que el Ejecutivo Federal suscriba, conforme al artículo 133 de la Norma Rectora. De igual forma, el Senado podrá terminar, denunciar, suspender, modificar, enmendar, retirar reservar y formular declaraciones interpretativas respecto de los Tratados Internacionales. Asimismo, el Senado analizará la política exterior del Ejecutivo Federal y ratificará los nombramientos de los responsables de la política exterior, seguridad, telecomunicaciones, justicia y áreas interrelacionadas.

\subsection{Artículo ochenta y nueve:}

- Fracción décima: Se faculta al Presidente de la Republica para dirigir la política exterior, debiendo observar los principios normativos de autodeterminación de los pueblos, no intervención, 
solución pacífica de las controversias, proscripción de la amenaza o uso de la fuerza en las relaciones internacionales, igualdad jurídica entre los Estados, la cooperación internacional para el desarrollo, el respeto, la protección y promoción de los derechos de los humanos y la lucha por la paz y la seguridad internacionales; además, el Ejecutivo Federal, podrá celebrar los Tratados Internacionales, conforme a la aprobación del Senado de la República, en los términos del artículo 76, fracción primera y el 133 de la Norma Rectora. Además, podrá terminar, denunciar, suspender, modificar, enmendar, retirar reservas y formular declaraciones interpretativas al respecto, sometiéndolos a la aprobación del Senado.

2.6 Artículo ciento cuatro: precisa que los Tribunales de la Federación, conocerán:

- Fracción primera: De los procedimientos relacionados con delitos del orden federal, en los términos del artículo 15 y vinculado al 18 de la Norma Rectora.

- Fracción segunda: De las controversias civiles o mercantiles interrelacionadas con la legislación federal o los Tratados Internacionales.

- Fracción cuarta: De las controversias de derecho marítimo, interrelacionado con los artículos 27, 42, 48, 73, 117 y 118 de nuestra Norma Rectora, de manera principal.

\subsection{Artículo ciento cinco:}

- Fracción segunda: En dos incisos, el b y el g. Inciso b). En cuanto al primero, se expresa que la Suprema Corte de Justicia de la Nación, conocerá de las acciones de inconstitucionalidad, que tengan por objeto plantear una posible contradicción entre la Norma Rectora o Constitución y una de carácter general, cuando sea planteada por el equivalente al 33\% de los integrantes del Senado, en contra de los Tratados Internacionales celebrados por el Estado Mexicano.

Inciso g). En este caso, la Comisión Nacional de los Derechos Humanos, podrá plantear la acción de inconstitucionalidad ante la Suprema Corte de Justicia de la Nación, en contra de los Tratados Internacionales en que México haya sido parte. 
2.8 Artículo ciento treinta y tres. Precisa que la Norma Rectora o Constitución, las leyes del Congreso Federal y los Tratados Internacionales que estén de acuerdo con la misma, los ya celebrados y que sean signados por el Ejecutivo Federal y aprobados por el Senado de la República, serán la Ley Suprema en toda la Unión; por los que los jueces de los entes federados, deberán de dar supremacía a la Norma Rectora, a contrario sensu de lo que pudiese disponer su norma interna. Con lo anterior, queda clara que en México, desde que existen estas disposiciones se encuentra el control difuso, copiado de los EUA, no bien entendido ni aplicado; asimismo, se interrelaciona con las disposiciones del artículo primero de la propia Norma Rectora, al señalar la supremacía constitucional y cómo debe aplicarse.

Artículos de la Norma Rectora o Constitución de México que se refieren a los derechos de los humanos o al derecho internacional:

Derechos de los Humanos:

1. Artículo primero: en cuatro ocasiones. En el párrafo primero, al reconocer los derechos de los humanos o de toda persona dentro del territorio nacional; dentro del segundo párrafo en cómo deben ser interpretadas las Normas Rectoras e Internacionales en mayor beneficio de las personas humanas; se expresa en el tercer párrafo que las autoridades deberán proteger los derechos de los humanos dentro del ámbito de sus competencias y en el quinto párrafo, existe el señalamiento de que se prohíbe toda discriminación que afecte los derechos y libertades de las personas.

2. Artículo segundo, apartado A, fracción segunda: El cual reconoce que nuestra Norma Rectora garantiza el derecho de los pueblos y comunidades originarias 0 autóctonas a la libre autodeterminación y que tendrán autonomía para aplicar sus propios sistemas normativos en la regulación y solución de sus conflictos internos, debiéndose sujetar a los principios de la Constitución o Norma Rectora, con respeto a las garantías individuales, a los derechos de los humanos y a la dignidad de las personas.

3. Artículo tercero: Dicta que la educación que imparta el Estado 
tenderá a desarrollar de manera armónica e integral las facultades del ser humano, fomentando el amor a la Patria, el respeto a los derechos de los humanos, la conciencia de la solidaridad internacional, la independencia y la justicia; asimismo, deberá contribuir a la mejor convivencia humana, respetar la diversidad cultural, la dignidad de la persona, la integridad de la familia, la convicción del interés general de la sociedad, los ideales de fraternidad e igualdad de derechos, evitando los privilegios de razas, religión, grupos, sexos o individuos.

4. Artículo quince. Como ya se apuntó, se prohíbe la extradición de personas a las que se les hayan violentado sus derechos como seres humanos.

5. Artículo veintinueve. La suspensión de los derechos de los humanos y sus garantías se hará con efectos generales, sin discriminación en un tiempo y espacio determinados.

Derecho internacional, de manera directa o indirecta:

1. Artículo tercero. Como se expresó, la educación deberá desarrollar la conciencia de la solidaridad internacional, en la independencia y en la justicia.

2. Artículo sexto: El Estado deberá garantizar el derecho de usar las tecnologías de la información y comunicación, servicios de radiodifusión, telecomunicaciones, banda ancha e Internet.

Apartado A. El organismo garante de poder utilizar la información pública, deberá velar porque el Estado Mexicano rinda cuentas en términos de ley.

Apartado B. En materia de radiodifusión y telecomunicaciones, el Estado garantizará a la población su integración a la sociedad de la información y el conocimiento, a través de políticas de inclusión digital universal con metas anuales y sexenales.

3. Artículo séptimo: Se permite la libertad de difundir opiniones, información e ideas a través de cualquier medio.

4. Artículo onceavo. Toda persona cuenta con libertad de tránsito interna y externa en el país. Las autoridades administrati- 
vas establecerán las bases para la emigración, inmigración y salubridad general dentro de la República, así como extranjeros perniciosos residentes en el país.

5. Artículo doceavo. En México no se conceden títulos de nobleza o derechos hereditarios, ni se les dará validez a los otorgados por cualquier país.

6. Artículo quince. Señala la reciprocidad internacional en materia de extradición y en el respeto a los derechos de los humanos en dichas cuestiones.

7. Artículo veintiuno. El Ejecutivo Federal podrá, previa aprobación del Senado de la República, reconocer la jurisdicción de la Corte Penal Internacional, según caso específico.

8. Artículo veinticuatro. Derecho a la libertad de convicciones éticas, conciencia y moral.

9. Artículo veintisiete: Párrafo quinto: Corresponde a la Nación el dominio directo de los recursos naturales de la plataforma continental y de los zócalos marinos de las islas, minerales y toda materia orgánica e inorgánica en la extensión y límites que fije el Derecho Internacional.

Párrafo sexto: Son propiedad de la Nación las aguas de los mares territoriales en la extensión y términos que fije el Derecho Internacional.

Párrafo séptimo: El dominio de la Nación sobre los recursos de la plataforma continental y aguas será inalienable e imprescriptible.

Párrafo octavo: Los hidrocarburos en el subsuelo son propiedad de la Nación.

Párrafo noveno: La Nación ejerce en una zona económica exclusiva situada fuera del mar territorial y adyacente a éste, los derechos de soberanía; la zona económica exclusiva será de doscientas millas náuticas, a partir de la línea de base desde la cual se mide el mar territorial.

10. Artículo veintiocho: Prohíbe los monopolios y las prácticas monopólicas, establece la Comisión Nacional de Hidrocarburos y la Comisión Reguladora de Energía, interrelacionadas con las 
cuestiones señaladas dentro del artículo 27 de la Norma Rectora. Se crean el Banco de México, la Comisión Federal de Competencia Económica y el Instituto Federal de Telecomunicaciones.

11. Artículo veintinueve, con relación al 119: La suspensión de los derechos de los humanos y sus garantías interrelacionados con la obligación de los poderes federales de proteger a los entes federados contra toda invasión o violencia exterior.

12. Artículo treinta: Se reconocen como bases o fuentes de la nacionalidad en México el ius soli et ius sanguini; además del derecho de sangre y suelo, se puede obtener la nacionalidad por naturalización.

\section{Artículo treinta y uno: Obligaciones de los mexicanos.}

14. Artículo treinta y dos: Se evitarán los conflictos por doble nacionalidad; los cargos y funciones constitucionales establecidos para mexicanos requiere de esa única calidad, por lo que no permitirá la doble nacionalidad, como lo es el caso del servicio en el ejército, policía o seguridad pública, en tiempos de paz, sólo podrán servir mexicanos por nacimiento. El mismo trato será para los capitanes, pilotos, patrones, maquinistas, mecánicos y todo el personal que tripule embarcación o aeronave con bandera o insignia mercante mexicana. Los mexicanos serán preferidos a los extranjeros en igualdad de circunstancias cuando no sea indispensable la calidad de ciudadano.

15. Artículo treinta y tres: Los extranjeros gozarán de los derechos de los humanos en igualdad de circunstancias y conforme a la Norma Rectora o Constitución; el Ejecutivo Federal podrá expulsar a extranjeros previa garantía de audiencia; los extranjeros no deberán inmiscuirse en los asuntos políticos del país.

16. Artículo treinta y cuatro: Son ciudadanos de la República, los mexicanos mayores de 18 años y que tengan un modo honesto de vivir.

17. Artículo treinta y siete: Ningún mexicano por nacimiento perderá su nacionalidad, sólo los que la hayan adquirido por naturalización la perderán si se hacen pasar por extranjeros o por residir cinco años consecutivos en el extranjero. La ciudadanía 
se perderá si se aceptan títulos nobiliarios extranjeros, se presten servicios oficiales al extranjero sin permiso del Ejecutivo Federal, se acepten condecoraciones extranjeras sin permiso del Presidente de la República (excepto el propio Ejecutivo Federal, senadores, diputados federales y ministros de la Suprema Corte de Justicia de la Nación, lo cual es discriminatorio); por admitir de otro país títulos o funciones sin permiso del Ejecutivo Federal, excepto títulos literarios, científicos o humanitarios y por ayudar en contra de la Nación a un extranjero o gobierno ajeno en reclamación diplomática o ante un tribunal internacional.

18. Artículo setenta y tres: Fracción octava: El Congreso Federal está facultado para dar las bases para que el Ejecutivo Federal pueda celebrar empréstitos, interrelacionado con el artículo 117 - VIII de la Norma Rectora.

Fracción décimo séptima: El Congreso Federal dictará las leyes relativas a las comunicaciones.

Fracción vigésima novena M: El Congreso Federal podrá dictar las leyes de seguridad nacional, interrelacionado con los artículos 117, 118, 119 y 29 de la Norma Rectora, de manera principal, además del 76 y 89.

Fracción vigésima novena O: El Congreso Federal legislará en materia de protección de datos personales en posesión de particulares, con relación a los artículos sexto y 16 de manera principal de la Norma Rectora.

Fracción vigésima novena S: Idem al anterior y vinculado al asunto de la transparencia.

19. Artículo setenta y seis: Fracción primera: El Senado de la República está facultado para analizar la política exterior que desarrolle el Ejecutivo Federal, conforme a los principios expresados en la fracción décima de dicho precepto. Asimismo, deberá aprobar conforme al artículo 133 y 89, los Tratados Internacionales que firma el Ejecutivo Federal.

Fracción segunda: El Senado de la República, ratificará los nombramientos que efectúe el Ejecutivo Federal en materia de relaciones exteriores y seguridad nacional.

Fracción tercera: El Senado de la República autorizará la salida del 
país de tropas nacionales, el paso de tropas extranjeras por México y la estación hasta por un mes en aguas mexicanas de naves extranjeras.

Fracción cuarta: El Senado de la República aprobará la disposición de la Guardia Nacional.

Fracción décima primera: El Senado de la República, deberá consentir la Estrategia Nacional de Seguridad Pública.

20. Artículo ochenta y nueve: Fracción primera: El Ejecutivo Federal promulgará y ejecutará las leyes que expida el Congreso Federal.

Fracción segunda: El Presidente de la República nombrará a su gabinete y a los responsables del servicio exterior mexicano.

Fracción tercera: El Ejecutivo Federal, deberá, con aprobación del Senado, nombrar a los embajadores, cónsules, responsables de las áreas de telecomunicaciones, energía y competencia económica.

Fracción cuarta, quinta, sexta, séptima y octava: Son atribuciones del Presidente de la República, nombrar a los altos mandos del Ejército, Armada y fuerza Aérea, preservar la seguridad nacional, disponer de la Guardia Nacional y declarar la guerra en nombre de la República.

Fracción décima: Dirigir la política exterior y celebrar los Tratados Internacionales conforme a lo señalado en los artículos 76 y 133 de la Norma Rectora.

Fracción treceava: El Ejecutivo Federal habilitará los puertos, aduanas marítimas y fronterizas y determinará su ubicación.

\section{Conclusiones:}

Primera. La Norma Rectora o Constitución es el acta de nacimiento del Estado, sujeto de Derecho Internacional, Supranacional y Planetario.

Segunda. Del análisis de más de doscientos documentos constitucionales o diversas Norma Rectoras en el planeta, se deduce que todas cuentan con disposiciones internas relativas al derecho externo, internacional, supranacional o planetario. 
Tercera. Desde la Constitución de los EUA, que sigue siendo la misma, todas las que han regido en México y las que se han aprobado por los diversos pueblos en el planeta, cuentan con reglas de orden externo.

Cuarta. El derecho interno, se encuentra en proceso de armonización con las normas internacionales, supranacionales y planetarias.

Quinta. Dicha tendencia, nos lleva al reconocimiento de normas, a su equivalencia, armonización, congruencia, coherencia y sistematizaciones similares, los que nos lleva, de manera directa a los derechos planetarios.

\section{Propuestas:}

1. Que en México se consulte al pueblo para que se aprueben los compromisos internacionales, tratados o instrumentos que influirán en los derechos de las personas en México.

2. Es necesario que se vaya construyendo un parlamento planetario en donde se discutan los grandes problemas del planeta, el cual se debe sujetar a un orden, interés y derecho en torno a dicho ente vivo.

3. La afectación de todos los seres vivos que habitamos este maravilloso planeta debe ser cuidado por la conciencia de todos; ya que los intereses de algunos no puede estar por encima del orden o interés planetario.

4. Se debe estudiar, por los seres humanos, la planetología. 
Algunas propuestas para avanzar en la reforma integral de la Constitución General de la República, Carlos Moyado y Jesús Covarrubias (coordinadores), Editorial Campesinos de México por la Democracia, México, 2002.

Análisis interdisciplinario de la Declaración Americana de los Derechos de los pueblos indígenas, UNAM, México, 2001.

COVARRUBIAS DUEÑAS, José de Jesús, EI Paradigma de la Constitución, Porrúa, México, 2008. Municipal en México, Porrúa, Segunda Edición, México, 2008.

constitucionalismo en México,' Porrúa, México, 2010.

Constitución Política de México (Siglos XX-XXI), Segunda edición, Porrúa, México, 2010.

logía Jurídica en México, una segunda aproximación, Universidad de Guadalajara, segunda edición, México, 2010.

rechos Planetarios, Porrúa, México, 2011.

Los De-

DE PINA, Rafael, DE PINA VARA, Rafael, Diccionario de Derecho, Porrúa, México, 1993.

Diccionario de la Lengua Española, 20ª. Edición, Editorial Espasa Calpe, Madrid, España.

Diccionario de Mexicanismos, Academia Mexicana de la Lengua, Siglo XXI editores, México, 2010. 
Enciclopedia de México, Tomos 1-14, SEP, 1988.

Enciclopedia política de México, XII Tomos, José de Jesús Covarrubias Dueñas (Coordinador), Senado de la República, Instituto Belisario Domínguez, México, 2010.

FERNÁNDEZ FERNÁNDEZ, José M., Diccionario Crítico de Ciencias Sociales, Román Reyes (director), Universidad Complutense de Madrid www.ucm.es/info/eurotheo/diccionario/M/mov_indigenas.htm

ISENSSE, El pueblo como fundamento de la Constitución, Anuario de Derechos Humanos, Nueva Época, Vol. 6, 2005.

KYMLICKA, Will, Ciudadanía multicultural, Paidós, España, 1996.

La Constitución de 1812: Miradas y perspectivas, Revista de Pensamiento Jurídico "teoría y derecho" número 10, Tirant lo Blanch, 2011.

Los Derechos del Pueblo Mexicano, México a través de sus Constituciones, Tomos I-VII, SCJN, Senado de la República, México, 2012.

MANCISIDOR, José, Historia de la Revolución Mexicana, cuarta edición, Costa-amic editores, México, 1981.

MIRANDA TORRES, Roxana, COVARRUBIAS DUEÑAS, José de Jesús, La Nomología de las Comunidades Precuauhtemicas en México, Gobierno del Estado de Oaxaca, México, 2008.

Supremacía Constitucional, Marcos del Rosario Rodríguez (coordinador), Universidad Panamericana, Porrúa, México, 2009. 
TENA RAMÍREZ, Felipe, Leyes Fundamentales de México 1808 - 1998, vigésima primera edición, Porrúa, México, 1998.

TOINET, Marie-France, El sistema político de los Estados Unidos, Fondo de Cultura Económica, México, 1994.

ZEA, Leopoldo et al, América Latina en sus ideas, Siglo XXI editores, 1986, México. 